\title{
Leitura na Educação de Jovens e Adultos e a formação de leitores
}

\author{
Marinaide Queiroz Freitas*
}

Valéria Campos Cavalcante**

\section{Resumo}

Este artigo é um recorte de uma pesquisa realizada em 2009, que teve como objetivo analisar o processo de leitura nas situaçóes de sala de aula das turmas de pós-alfabetização da Educação de Jovens e Adultos (EJA), em escolas públicas municipais e estaduais em Maceió, tendo como categorias de análise leitura, gêneros textuais e eventos e práticas de letramento. A natureza da investigação configurou-se como qualitativointerpretativa, baseada em estudo de caso. Os resultados do estudo indicaram que nas escolas pesquisadas não se compreende a importância da leitura para a ampliação do letramento dos sujeitos, uma vez que ela permanece ocupando um lugar secundário nos projetos pedagógicos e, consequentemente, na prática de sala de aula. Na prática de uma professora, que foi objeto da pesquisa e que comentamos neste artigo, ficaram explícitas dificuldades no trato com a leitura e letramento dos educandos, sobretudo, no que disse respeito aos fundamentos linguísticos, necessários às atividades para trabalhar a leitura. Sendo assim, a profissional age muitas vezes baseada na intuição, ou transplanta para a modalidade práticas pedagógicas que vivenciou em seu período de escolarização.

Palavras-chave: Educação de Jovens e Adultos. Linguagem e Educação. Prática docente.

\footnotetext{
* Doutora em Letras e Linguística pela Universidade Federal de Alagoas (UFAL). Professora do curso de Pedagogia e da Pós-graduação em Educação Brasileira na UFAL.

** Mestre em Educação e Doutoranda em Educação pela UFAL. Professora do Centro de Estudos Superiores de Maceió (CESMAC).
} 


\section{Considerações Iniciais}

Neste século XXI, um dos principais desafios das escolas públicas do Brasil é fazer com que os sujeitos que as frequentam, principalmente na Educação de Jovens e Adultos (EJA), consigam superar o analfabetismo funcional ${ }^{1}$. Mesmo existindo, de certa maneira, um forte discurso em âmbito oficial em transformar neoleitores em leitores experientes, percebe-se que os projetos federais ${ }^{2}$ surgem tentando incentivar o hábito da leitura nas escolas com grandes dificuldades.

Por outro lado, as políticas públicas de leitura ${ }^{3}$ têm atuado quase sempre fragmentadas, não incentivando uma formação continuada específica para os/ as educadores/as e para aqueles/as que são responsáveis pelas salas de leitura, que em sua maioria são professores/as readaptados, em desvio de função da regência de sala de aula. Focalizam apenas a necessidade das escolas e dos/ as professores/as incentivarem o gosto pelo ato de ler, diante de um acervo predominantemente de livros didáticos.

Outra lacuna existente nas escolas, quando da realização de ações para se despertar o prazer pela leitura, é que não se tem explícito a definição sobre que tipo de leitor se pretende formar. Não se reflete sobre os aspectos referentes aos eventos e práticas de letramento ${ }^{4}$ que estão ocorrendo nas salas de aula, da mesma forma, não se enfatiza a importância dos professores conhecerem as teorias sobre processamento de leitura, conhecimento esse necessário, mas que na sua maioria, não tiveram na sua formação inicial.

Reconhecemos que a responsabilidade em formar leitores experientes não deva ser atribuída apenas às instituiçóes escolares e aos professores/as, como bem enfatiza Antunes (2009, p. 188), "se a escola é concebida uma prioridade nesta tarefa, não se exclui, contudo, a intervenção de outras instituiçôes sociais, como a família, os meios de comunicaçâo [...] e tantas outras", ressaltamos que a maioria dos/as educandos/as, da escola pública por falta de recursos seus e de suas famílias, só têm convívio mais prolongado com portadores de textos nas escolas.

A prática da leitura é tida como processo que permite ao sujeito compreender a sua razão de ser no mundo, buscando, incessantemente, mais conhecimentos sobre a realidade (SILVA, 1999). Dentro deste contexto, leitores experientes são aqueles que leem rapidamente, sem movimentar lábios, perceptivelmente e sem subvocalização, não apenas decifrando códigos, mas conhecendo as funçóes sociais dos textos (KLEIMAN, 1999). 
Estudiosos em leitura, a exemplo Bajard (1994, 2007), enfatizam que não existe um só tipo de leitura, há também focos de leitura. Nessa perspectiva, Koch (2007) define que existem três focos de leitura: o primeiro, voltado para as ideias do autor; o segundo centra-se no texto, ou seja, no reconhecimento do sentido das palavras e sua estrutura e o terceiro foco se pauta na interação autor-texto-leitor, isto é, "a leitura de um texto exige do leitor bem mais que o conhecimento do código linguístico, uma vez que o texto não é simples produto da codificação de um emissor a ser decodificado por um receptor passivo" (KOCH; ELIAS 2006, p. 11), mas que depende de ambos (autor-leitor) para a construçáo dos sentidos.

Outra habilidade relacionada à leitura refere-se ao conhecimento do gênero textual. Segundo Marcuschi (2008), o gênero é facilmente usado para referir uma categoria distintiva de discussáo de qualquer tipo, falado ou escrito, com ou sem aspiraçóes literárias. Tratando de tipo textual, Marcuschi (2008, p. 147), afirma que "[...] em geral os tipos textuais abrangem categorias conhecidas como: narração, argumentação, exposição, descrição, injunção".

Nesse sentido, as práticas de leitura e escrita exercidas no contexto escolar não podem ser desvinculadas dos contextos sócio-culturais reais dos educando, em seu processo de alfabetização e letramento, mesmo porque à medida que a sociedade tornou-se grafocêntrica, bem como, grande parte das interações sociais, os usos e funçōes da escrita foram se multiplicando e diversificando, que apenas saber ler e escrever se revelou insuficiente.

Para que os sujeitos da EJA tornem-se leitores experientes e elevem o seu nível de letramento, observa-se que a responsabilidade tem recaído, quase que exclusivamente, na postura do professor em sala de aula, principalmente na EJA. Isso porque os educandos dessa modalidade sempre reafirmam o vínculo criado com o professor e a tendência à imitação. Dessa forma, o cuidado de se ter exemplos positivos é fundamental. A referência para o aluno de um professor como modelo de leitor experiente e assíduo se torna ainda mais forte, uma vez que grande parte desses sujeitos não possuem fora da escola convivência com pessoas que tenham hábitos leitores, que possam servir como influência.

Os estudos vêm mostrando a exemplo de Cavalcante (2009) que a figura do professor da EJA representa fator determinante, não só na instituição do hábito da leitura, mas acima de tudo, como um formador de leitores, conforme destaca Silva (2002, p. 19): "O professor é o intelectual que delimita todos os quadrantes do terreno da leitura escolar. Sem sua presença atuante, sem seu 
trabalho competente, o terreno dificilmente chegará a produzir o benefício que a sociedade espera [...], ou seja, leitura e leitores assíduos".

Nesse sentido, ressaltamos a importância do educador enquanto mediador nas aulas de leitura, reconhecendo, portanto, que não há nenhum instrumento, ou tecnologia que o substitua, sendo assim, sua presença, seu exemplo, sua experiência representam a possibilidade de mediação entre os sujeitos alunos e os conhecimentos sistematizados por intermédio do domínio das habilidades de leitura e escrita que a sociedade vem exigindo.

Dessa maneira, os professores da EJA precisam garantir aos educandos um processo que ultrapasse a visão de apenas ensinar a ler e escrever, ou seja, um ensino de leitura que agregue as duas dimensóes do letramento: a individual, que se refere à alfabetização, e a sociocultural que envolve o uso e práticas de leitura e escrita (SOARES, 2003), para que o sujeito não regrida do seu processo de aprendizado.

Este artigo é um recorte de uma pesquisa ${ }^{5}$ que teve como objetivo analisar o processo de leitura nas situaçóes de sala de aula das turmas de pós-alfabetização da Educação de Jovens e Adultos (EJA), em escolas públicas situadas em Maceió, envolvendo as redes municipal e estadual, a partir da utilização dos gêneros textuais, visando à formaçáo de leitores. $\mathrm{O}$ estudo foi de natureza qualitativa e para sua realização recorremos ao estudo de caso e as orientaçóes da etnografia interacional. O estudo de caso é caracterizado por Gil (1991, p. 58) como um "[...] estudo profundo e exaustivo de ou de poucos objetos, de maneira que permita o seu amplo e detalhado conhecimento [...]".

A etnografia interacional possibilitou-nos a realizaçáo de um trabalho interpretativo e observacional que acompanhou o dinamismo dos elementos observados e dos fenômenos textuais. Para Nunes-Macedo et, al(2004), por meio das orientaçóes da etnografia interacional, pesquisadores têm investigado a sala de aula partindo do pressuposto de que essa é uma "comunidade culturalmente constituída" por meio da participação de diferentes sujeitos, que assumem diferentes papéis no processo de ensino-aprendizagem. Nessa perspectiva, a aprendizagem é definida situacionalmente por meio das formas em que professores e alunos constroem os padróes e práticas da vida de cada sala de aula (NUNES-MACEDO et al., 2004).

A abordagem metodológica foi auxiliada pela análise documental dos Projetos Político-Pedagógicos (PPP) das escolas investigadas, apoiadas 
pelas técnicas e instrumentos de coleta de dados. Os referidos dados foram coletados em: visitas, encontros, reuniōes, observaçóes em salas de aula, grupo focal com alunos e entrevista semiestruturada para identificarmos o perfil das professoras, objeto de estudo e a concepçáo de leitura. Tendo como categorias de análise: leitura, gêneros textuais, eventos e práticas de letramento. O estudo fundamentou-se em pesquisadores como: Bajard (1994, 2007), Kleiman (1989a, 1989b, 1999, 2004), Koch e Elias (2006), Marcuschi (2001), Nunes-Macedo et al. (2004), Sacconi (2001), Soares (1998, 2003, 2004), entre outros.

Os resultados das análises explicitados, neste recorte, deram-se a partir de dois blocos de interpretação: (a) caracterização de uma das escolas, que foi locus do estudo e caracterização dos sujeitos investigados - alunos e professora dessa Escola; e (b) análise de um evento de letramento observado em sala de aula e finalizamos com algumas consideraçôes.

\section{Caracterização}

\section{Da Escola foco da pesquisa}

A escola investigada é uma instituição pública do Ensino Fundamental da Secretaria Municipal de Educação de Maceió (SEMED). Situa-se na periferia urbana no município da capital alagoana. Para manter o anonimato decidimos dar-lhe o nome fictício de Escola Safira ${ }^{6}$. A referida instituição foi escolhida por conter grande quantidade de turmas de EJA do primeiro segmento, ao todo oito turmas, e por sua importância histórica enquanto formadora de trabalhadores no bairro onde está localizada.

A Escola Municipal de Ensino Fundamental Safira oferece, nos turnos diurnos, Educação Infantil, $1^{\text {a }}$ ao $5^{\circ}$ ano do Ensino Fundamental e no horário noturno, $1^{\circ}$ e $2^{\circ}$ segmentos da Educaçáo de Jovens e Adultos, sendo sete salas para atender ao $1^{\circ}$ segmento e quatro para atender ao $2^{\circ}$ segmento.

No tocante à leitura não há espaço específico para realização dessa prática fora das salas de aula, uma vez que o destinado a esse fim, a partir de 2008, foi desativado, sendo instalado um laboratório de informática, considerado mais necessário para os alunos. $\mathrm{O}$ acervo de livros que estava nesse local fora amontoado em uma sala de recurso ${ }^{7}$ que funciona anexa à escola. Esse espaço é inseguro, pouco iluminado, sem ventilação e comporta no máximo quinze 
alunos. Diante dessa improvisação, os professores não se sentem motivados para ocupá-lo e realizarem atividade com os alunos.

A Escola conta ainda com acervo limitado de livros, sendo a maioria, voltados para o público infantil. Para EJA, encontramos poucos livros paradidáticos de literatura.

\section{Dos(as) Alunos/as}

O quantitativo de 35 educandos/as que estavam frequentando a turma observada do primeiro segmento, no período de nossa investigação, eram na maioria do gênero masculino (60\%). Esses sujeitos são, em grande maioria, vítimas da indiferença, do desemprego e do descaso, socialmente estigmatizados e excluídos, e, muitas vezes, vítimas ou envolvidos em casos de violência. $\mathrm{Na}$ escola, como nos chama atenção Andrade (2004), de maneira geral são tratados como uma massa de alunos, sem identidade, qualificados sob diferentes nomes: repetentes, evadidos, defasados, relacionados diretamente ao chamado "fracasso escolar".

As turmas da EJA da escola Safira são compostas de adolescentes, jovens e adultos desempregados ou trabalhadores em situaçáo informal, idosos aposentados ou jovens e adultos que trabalham como: comerciários, donas de casa, pedreiros e porteiros, ganhando um salário mínimo ou menos. Sáo sujeitos oriundos da periferia - são os "fugitivos da seca" que assola a zona rural. Acreditamos que isso se deva a uma quase inexistência de políticas públicas que gerem empregos e rendas para a população do Estado e do município, tanto na zona urbana como na rural.

Diante das evidências, esses educandos e educandas se autodeclaram de cor branca e de religiáo católica. Isso ocorre porque esses sujeitos não reconhecem suas diversidades culturais e sociais, pois desde sempre a escola impôs um currículo único, no qual não é respeitada nem a diversidade cultural, nem a realidade dos educandos, como Giroux (1988, p. 63-64) nos alerta: "Suas peculiaridades, contradiçóes e a qualidade do que é vivido ficam dissolvidas sob a ideologia do controle e do gerenciamento. Em nome da eficiência, os recursos e a riqueza das histórias de vida dos estudantes são ignorados".

Grande parte desses educandos já frequentou escolas em horário diurno durante anos, tendo uma história escolar marcada por múltiplas reprovaçóes. Por conta da idade considerada "avançada" (mais de 15 anos) e a Escola náo 
os querendo no horário diurno, acabam sendo "empurrados" para a referida modalidade. Dessa maneira, podemos observar uma enorme demanda de jovens com idade entre 15 e 18 anos frequentando o ensino noturno. Alguns deles, não se escolarizaram no tempo exigido por lei, por terem sido obrigados a realizar trabalhos infantis/escravizados no período de infância.

São pessoas que possuem conhecimentos adquiridos na vida cotidiana, por meio de experiências advindas das interaçóes das agências de letramento como: família, comunidade, mundo do trabalho e em saídas e entradas da escola. Podem ser caracterizados(as), de acordo com a visão de Freire (2001), como pessoas que possuem uma leitura de mundo que antecede a leitura da palavra. Em geral, esses sujeitos voltam à escola reconhecendo que o aprendizado alcançado anteriormente, de maneira formal ou informal, não lhes garantiu a independência e a inclusão desejada numa sociedade competitiva e excludente.

Quando da realização do grupo focal com esses alunos ouvimos sobre as leituras que realizam no ambiente doméstico, bem como sobre livros que possuem, as falas marcaram a convivência com livros didáticos e, de forma limitada, o acesso a revistas, conforme registramos a seguir:

[...] não leio por que saio de casa cedo, trabalho o dia todo ainda venho para escola, por isso só tenho tempo aqui na escola [...] tenho sim, tenho muitas revistas em casa; (sv), tenho vários livros em casa, principalmente de matemática, eu gosto muito de matemática (sv) [...], lá em casa tem um montão de livro assim.. aqueles professora... que a escola deu o ano passado, era bem uns dez livros...(sv), eu só tenho os livro que e eu meus filhos ganharam na escola, mas não tenho muito tempo pra ler em casa só leio na escola. [...], eu leio, mais no final de semana, pego o livro e leio (sv), eu lei cinco horas da manhã antes de sair pra trabalhar, enquanto a mulher faz o café, eu leio esse livro aqui [o aluno mostra o livro didático $]^{8}$.

Dentre essas falas, há uma bastante reveladora, que representa a realidade da maioria dos trabalhadores-alunos da educaçáo de jovens e adultos: "[...] não leio porque saio de casa cedo, trabalho o dia todo, ainda venho para a escola, por isso só tenho tempo aqui na escola". Analisando esse trecho coletado podemos afirmar que mesmo reconhecendo que a leitura ocorre em diversos lugares, para a maioria de nossos educandos da EJA em Alagoas, por falta de recursos 
seus e de suas famílias, esses sujeitos têm um convívio mais prolongado com portadores de textos nas escolas, ou mesmo quando estão fora da escola percebese a influência da instituição como formadora de leitores.

\section{Da Professora ${ }^{9}$ pesquisada}

A professora tem formação inicial em Pedagogia, tinha na época da pesquisa 43 anos, possui pós-graduação (lato sensu), em psicopedagogia, não cursou à época a disciplina Educação de Jovens e Adultos, ofertada no referido curso pela Universidade Federal de Alagoas, local onde estudou, em 2005. Não teve na sua formação, estudos específicos sobre leitura. Nesse sentido, afirmou: "Não, eu não lembro de ter estudado na faculdade uma disciplina de leitura. [...] Nas formaçóes continuadas que já participei quase não se fala de leitura é mais escrita”.

A partir dos dados coletados, ficou explícito que as experiências de leitura que professora viveu no seu cotidiano vêm influenciando nas práticas que desenvolve em sala. Ao analisarmos nossas entrevistas e questionários detectamos que a professora atuava também na Educação Infantil em uma escola pública estadual e, no turno noturno se ocupava com a EJA, afirmou, quando da entrevista "[...] que, estava especificamente na EJA por se identificar com a proposta da referida modalidade".

\section{Análise de um evento de letramento das aulas de leitura da EJA}

Das 10 aulas observadas na sala de aula de pós-alfabetização em EJA, na Escola Safira, que segundo a professora tinham o foco no ensino de leitura, escolhemos a que se segue para comentarmos neste artigo.

Nesse evento, a professora utiliza um texto informativo, que pertence ao domínio discursivo instrucional (MARCUSCHI, 2008).

$\mathrm{Na}$ observação, deste evento de letramento, percebemos que a professora, embora pergunte quem gostaria de ler o texto, em voz alta, por encontrar-se rouca, antes das respostas, ela elege uma aluna, mesmo havendo vinte alunos na sala de aula. A aluna, sempre foi a escolhida, em aulas anteriormente observadas. A docente sempre justificava que essa aluna sintetiza os critérios de boa leitora, que segundo a sua concepçáo realiza a leitura com um padrão de entonação e pontuação, conceito expresso na entrevista semiestruturada. 
A professora, naquele momento, estava transplantando o modelo de prática de leitura com o qual ela foi alfabetizada. Contou-nos, na entrevista, que aprendeu a ler por um modelo de leitura baseada na transmissão vocal: " $E u$ lembro que no meu tempo de escola a professora ou lia ou nos mandava ler voz alta. Eu na minha turma uso também muita leitura em voz alta, por que precisamos treinar muito para poder ler bem".

Fica explícito que a docente comunga da ideia de que um bom leitor é aquele que consegue "ler bem" em voz alta, respeitando a ortografia das palavras. Portanto, dava ênfase, durante as aulas de leitura, à expressão oral, pois a boa leitura é aquela em que se lê com a entonação correta, obedecendo aos sinais de pontuação. Ela não estava preocupada com o entendimento do texto ou com a funçáo social da leitura, contrapondo-se ao conceito de leitura enquanto interação.

Não cabe condenarmos a escuta de textos em sala de aula, pois acreditamos que deva sim ocorrer, no entanto, defendemos que essa forma de leitura náo pode ser a única privilegiada. Defendemos a concepçáo de que os alunos devam também, realizar suas próprias leituras para se tornarem leitores, uma vez que só se aprende a ler, lendo, conforme afirmam Silveira (2005a, 2005b), Solé (1998), entre outros autores. Ao priorizar em grande parte das aulas de leitura a "transmissáo vocal" de texto para a turma, percebe-se que o objetivo desses eventos de leitura era a exaltação da boa fluência e não a formaçáo de leitores de proficientes.

Não entendendo ou não querendo entender que o barulho das conversas da maioria dos alunos, na sala de aula, quando da leitura da aluna, poderia se constituir em um protesto daqueles, que nunca eram escolhidos, a professora toma uma atitude de reler o texto. Nessa segunda leitura, que é feita com excelente entonação e respeito à pontuação, apesar da rouquidão da professora, os alunos conversam menos.

Essa realidade foi sempre uma constante nas observaçóes. Sendo assim, esses eventos não configuravam o ato de ler propriamente dito, porque apoiando-nos em Bajard (2007) a transmissão vocal, caracteriza-se pela figura de um proferidor diante de uma plateia, evidenciando, portanto, a presença de um emissor e de receptor/es, e segundo o autor, em situaçóes desse tipo não se pode considerar que houve leitura.

Quando da observação, em outra escola e em sala de EJA, houve a predominância desse mesmo formato, demonstrando assim que a leitura proporcionada aos sujeitos alunos, segue um padrão que se manifestava pela 
leitura magistral da professora, servindo como modelo, diante de um público de expectadores que são liberados da procura de sentidos no texto, uma vez que conheceram o texto por intermédio da audição (BAJARD, 2007).

A concepção limitada de leitura dos/as educadores/as, a partir na lacuna deixada, tanto na formação inicial como continuada, é refletida no ensinoaprendizagem de leitura, no caso específico, nas classes da EJA, ou seja, um ensino de leitura padronizado seguindo passos repetitivos de: ler o texto, de preferência em voz alta, responder questionários, estudar gramática e redação, tudo isso acontecendo sem grande variação, durante todas as aulas que seriam destinadas à leitura, que se torna um mecanismo estafante e previsível (SILVA, 1999).

Nessas condiçôes, não se valoriza na EJA as diferentes formas de leitura para diversas situaçóes da vida, conforme nos lembra Silveira (2006), compartilhando das ideias de Solé (1998): existe a leitura para deleite (gêneros literários, anedotas, crônicas etc.); a leitura para trabalho (gêneros profissionais - relatórios, manuais de instruçóes,etc.) a leitura para estudo (gêneros didáticos - exposiçóes, dissertaçôes, ensaios etc.); a leitura para auto-ajuda (parábolas, fábulas, pensamentos etc.) e algumas outras funçóes sociais que a leitura assume na sociedade.

Com essa prática de ensino de leitura nas turmas da EJA, os alunos não conseguem atribuir significados ao que leem. Nestas condiçóes, os educandos ao se depararem com os textos nos eventos sociais de leitura, fora do contexto escolar, dedicam-se apenas à decifração dos signos, preocupando-se, principalmente, com a boa pronúncia das palavras. E acabam sendo condicionados a realizarem suas leituras "imitando" o modelo que lhes é oferecido na escola, e dessa forma são tratados como "minimamente leitores".

Essa falta de formaçáo dos professores da EJA, aliada à escassez de planejamento nas escolas, alimentam na nossa compreensáo a perpetuação dos altos índices de analfabetismo funcional tanto em relaçáo às crianças como aos jovens e aos adultos. Registramos a necessidade de se garantir oportunidades de formação continuada para os profissionais que atuam na EJA, para que eles/as tenham um espaço para refletir sobre sua prática e sobre sua própria formação enquanto leitores/as.

\section{Considerações finais}

Ao analisarmos a realidade pesquisada à luz da fundamentação teórica escolhida, constatamos que as práticas de letramentos presentes no cotidiano 
escolar das turmas da EJA, não possibilitaram um ensino de leitura que permitisse a inserção social dos sujeitos na sociedade letrada, uma vez que existem alguns empecilhos que a instituição escolar impóe aos sujeitos professores e alunos. Dentre eles, podemos mencionar que a Escola enquanto espaço leitor, não disponibilizava um ambiente exclusivo para que os alunos realizassem as suas próprias leituras. O único espaço disponível, além de ter um acervo limitado, é pequeno, não permite uma boa acomodação a quem frequenta, tem iluminação precária e se situa em local que falta segurança. Sendo assim, os eventos de letramento que a instituição oferta aos educandos do turno noturno, limitamse quase que exclusivamente aos que ocorrem em sala de aula.

Constatamos também que inexiste um planejamento para que os professores construam uma metodologia de intervenção que ressignifique o processo de aprender a ler, valorizando as interaçóes dos sujeitos/educandos com o mundo letrado e os usos sociais da leitura; aliado à falta de planejamento houve uma dificuldade na reproduçáo de textos, pela professora, a serem utilizados em sala de aula. Isso se revelou como um dos principais obstáculos para o desenvolvimento do trabalho gêneros. Na maioria das vezes, nas aulas, os alunos acompanhavam a leitura, só pela escuta, uma vez que não se disponibiliza cópias dos textos trabalhados.

Outro empecilho para a formação de leitores na escola é que a instituição não promove eventos de letramento fora de sala. Durante os seis meses de observação, houve apenas um momento em que acontecera uma discussão coletiva no pátio da escola, tendo como temática o trânsito.

Nas observações realizadas, percebemos que o ensino de leitura raramente ocorreu, a predominância foi o uso dos gêneros textuais, principalmente, para o trabalho com a gramática, demonstrando que a professora tem uma enorme dificuldade em trabalhar os aspectos linguísticos, estruturais ou as ideologias que os gêneros textuais possuíam.

Apesar do esforço demonstrado pela educadora, observou-se que essa profissional apresentou grandes dificuldades no trato com a leitura, o que pode acontecer devido a ausência na sua formação inicial e continuada, dos fundamentos linguísticos necessários para uma prática bem sucedida com a leitura. Assim sendo, age muitas vezes baseada, na intuiçẫo, ou transplantam para a modalidade práticas pedagógicas que vivenciaram em seus períodos de escolarização.

No sentido de minimizar essa situação, é importante que nos momentos de formação continuada criem situaçóes em que o professor se perceba enquanto 
leitor, aliadas às discussōes que o permita repensar as práticas de leitura presentes na escola, possibilitando-lhe a reflexão de sua própria representação de leitura e concepção didática, confrontando-as com um material teórico e com diferentes práticas alternativas de trabalho com a leitura, podendo contribuir, assim, para rompermos com o protótipo de ensino de leitura e de leitor que estão arraigadas à escola e que vem sendo reproduzidas ao longo dos séculos.

\section{Notas}

${ }^{1}$ Sujeitos que náo possuem ainda as competências necessárias para a realização de uma leitura fluente, portanto, não conseguem entender o significado do que leem, não conseguem produzir críticas das leituras que realizam, ou seja, são leitores que necessitam do suporte e das metodologias dos professores para se tornarem leitores experientes e maduros.

${ }^{2} \mathrm{O}$ MEC já demonstrou a sua preocupação, no entendimento de que uma política de formação de neoleitores, caminha além da aquisição e distribuição de acervo. Dessa forma, realizou, por intermédio da Secretaria de Educação Básica (SEB), a pesquisa denominada Avaliação Diagnóstica do Programa Nacional de Biblioteca na Escola (PNBE), cujo resultado pode ser lido em PAIVA. Em relação a Educação de Jovens e Adultos, por meio do edital no 44 de 2008 MEC/SECAD, incentivou dentre outras atividades, a realizaçáo pelas Universidades Públicas de Pesquisas sobre a formação de neo-leitores na EJA.

${ }^{3}$ Dentre essas açóes podemos enfatizar: programas voltados para a leitura, como o Pró-leitura, o Programa Nacional de Incentivo à Leitura (PROLER), Fome do Livro e Viva-leitura, Plano Nacional do Livro e Leitura (PNLL), assim como os programas mais específicos como o Projeto Literatura em Minha Casa, Programa Nacional de Biblioteca Escolar (PNBE), e o Programa Nacional do Livro Didático (PNLD).

${ }^{4}$ Prática de letramento - padróes culturais de uso da leitura e da escrita em uma situação particular, isto é, as pessoas trazem seu conhecimento cultural para uma atividade de leitura e escrita, definindo os caminhos para utilizar o texto escrito em eventos de letramento.Eventos de 
letramento - "[...] são as atividades particulares nas quais o texto escrito tem um papel. Essas atividades podem ter certa regularidade" (BARTON, 1994).

${ }^{5}$ Pesquisa denominada: Leitura na Educação de Jovens e Adultos e a Formação de Leitores, com fomento do PIBIC/UFAL/FAPEAL (2009). $\mathrm{O}$ foco da pesquisa foi investigar até que ponto os eventos e práticas de letramentos que os educandos da EJA estão tendo acesso no espaço escolar, especificamente, nas aulas de leitura, lhes possibilitam tornarem leitores experientes/letrados. A investigação foi norteada pela seguinte problematização: Qual o tratamento dado ao ensino de leitura nas salas de aula da Educação de jovens e Adultos, em escolas públicas na cidade de Maceió?

${ }^{6}$ Quando da pesquisa uma análise documental do seu Projeto PolíticoPedagógico, reelaborado no ano de 2008.

${ }^{7}$ A sala de recurso em Alagoas se configura como o espaço no qual são atendidos os estudantes caracterizados como especiais.

${ }^{8}$ As transcriçóes foram realizadas considerando as falas, no seu sentido literal e utilizamos os seguintes marcadores da Análise da Conversação:

- Sobreposição de vozes (sv)

- Entonação enfática Maiúscula.

- Textos lidos negrito.

- Professora P.

- alunos s__ são identificados pela inicial maiúscula do nome, quando há diálogo.

- Alunos___ quando tomam o turno são identificados pela letra $\mathrm{A}$ (maiúscula) mais a numeração de acordo com o turno.

- Comentários do transcritor $=$ (comentários) .

${ }^{9}$ Os critérios para a escolha da professora foram: possuir vínculo efetivo com a SEMED, por meio de concurso público; atuar na EJA há mais de três anos; ser regente em turma de pós-alfabetização. 


\section{REFERÊNCIAS}

ANDRADE, Eliane Ribeiro. Os jovens da EJA e a EJA dos jovens. In: BARBOSA, Inês Oliveira; PAIVA, Jane (Org.). Educação de jovens e adultos. Rio de Janeiro: DP\&A, 2004.

ANTUNES, Irandé. Aula de português: encontro e interação. 8. ed. São Paulo: Parábola Editorial, 2009.

BAJARD, Élie. Da escuta de textos à leitura. São Paulo: Cortez, 2007.

BAJARD, Élie. Ler e dizer: compreensão e comunicação do texto escrito. São Paulo: Cortez, 1994.

BARTON, David. Literacy: an introduction to the ecology of written language. Oxford: Blackwell, 1994.

CAVALCANTE, Valéria Campos. Leitura na Educação de Jovens e Adultos: um estudo de eventos e práticas de letramentoem salas de aula do $1^{\circ}$ segmento. 2009. Dissertaçáo (Mestrado em Educação) - Universidade Federal de Alagoas, Maceió, 2009.

GIL, Antônio Carlos. Métodos e técnicas de pesquisa social. São Paulo: Atlas, 1991.

GIROUX, Henry. A escola crítica e a política cultural. 2. ed. Sáo Paulo: Cortez, 1988.

FREIRE, Paulo. A importância do ato de ler: em três artigos que se completam. 42. ed. São Paulo: Cortez, 2001.

KLEIMAN, Ângela B. Leitura: ensino e pesquisa.Campinas, SP: Pontes, 1989a.

KLEIMAN, Ângela B. Texto e leitor. Campinas, SP: Pontes, 1989b.

KLEIMAN, Ângela B. (Org.). Os significados do letramento: uma nova perspectiva sobre a prática social da escrita. Campinas, SP: Mercado de Letras, 1999.

KLEIMAN, Ângela B. Abordagens da leitura. Belo Horizonte: Scripta, 2004.

$\mathrm{KOCH}$, Ingedore, V. Villaça; ELIAS, Vanda Maria. Ler e compreender: os sentidos do texto. São Paulo: Contexto, 2006. 
MARCUSCHI, Luiz Antônio. Letramento e oralidade no contexto das práticas sociais e eventos comunicativos. In: SIGNORINI, Inês (Org.). Investigando a relaçáo orallescrito eas teorias do letramento. Campinas, SP: Mercado das Letras, 2001.

MARCUSCHI, Luiz Antônio. Produção textual: análise de gêneros e compreensão. São Paulo: Parábola, 2008.

NUNES-MACEDO, Maria do Socorro Alencar et al. A constituição das interaçôes em sala de aula e o uso do livro didático: análise de uma prática de letramento no primeiro ciclo. Revista Brasileira de Educação, Rio de Janeiro, n. 25, 2004.

PAIVA, Jane et al. Programa Nacional Biblioteca na Escola (PNBE): leitura e biblioteca nas escolas públicas brasileiras. Brasília, DF: MEC, 2008

QUEIROZ, Marinaide Lima de et al. Gêneros textuais na educação de jovens e adultos em Maceió. Maceió, AL: FAPEAL, 2004.

SACCONI, Antônio Luiz. Dicionário essencial da língua portuguesa. Sáo Paulo: Atual, 2001.

SILVA. Ezequiel Theodoro da. De olhos abertos: reflexôes sobre o desenvolvimento da leitura no Brasil. 2. ed. São Paulo: Ática, 1999.

SILVEIRA, Maria Inez Matoso. Modelos teóricos e estratégias de leitura: suas implicaçōes no ensino. Maceió: Edufal, 2005a.

SILVEIRA, Maria Inez Matoso. Análise de gênero textual: concepção sócioretórica. Maceió: Edufal, 2005b.

SILVEIRA, Maria Inez Matoso. A importância da leitura instrumental na escola. Revista Educação, Maceió, agosto, 2006.

SOARES, Magda. Letramento: um tema em três gêneros. Belo Horizonte: Autêntica, 1998.

SOARES, MAGDA. Letramento e escolarização. In: RIBEIRO, Vera Masagão (Org.). Letramento no Brasil: reflexóes a partir do INAF 2001. São Paulo: Global, 2003.

SOARES, Magda. Letramento e alfabetização: as muitas facetas. Revista Brasileira de Educação, Rio de Janeiro, n. 25, 2004.

SOLÉ, Isabel. Estratégias de leitura. Porto Alegre, RS: Artmed, 1998. 


\section{Lectura en Educación de Jóvenes y Adultos y formación de lectores}

\section{Resumen}

Este artículo es parte de una encuesta realizada en 2009, que tuvo como objetivo analizar el proceso de la lectura en situaciones áulicas en las clases de post- alfabetización en la Educación de Jóvenes y Adultos (EJA) en las escuelas municipales y estatales, en Maceió, teniendo como categorías de análisis de lectura, géneros textuales y eventos y prácticas de alfabetización. La naturaleza de la investigación se configura a partir de un abordaje cualitativo-interpretativo, basado en estudios de caso. Los resultados del estudio indicaron que las escuelas encuestadas no entienden la importancia de la lectura para ampliar la alfabetización de los sujetos, ya que esta continúa ocupando un lugar secundario en los proyectos pedagógicos y por lo tanto en el aula. En la práctica docente de una maestra que fue objeto de investigación y que presentamos en este artículo, fueron evidentes las dificultades en el trabajo con la lectura y la alfabetización entre los estudiantes, sobre todo en relación a los fundamentos lingüísticos, necesarios para las actividades de la lectura. Por lo tanto, la profesional actúa a menudo basada en la intuición o recurre a prácticas pedagógicas que ha experimentado en su período de escolarización.

Palabras claves: Educación de Jóvenes y Adultos. Lenguaje y Educación. Práctica docente.

\section{Reading in youth and adult education and reader development}

\section{Abstract}

This article is part of a research paper conducted in 2009, which aimed to analyse the reading process used in Youth and Adult Education (EJA) post-literacy classes in municipal and state schools in Maceió, in the light of the analysis of reading, textual genres and literacy events and practices. This qualitative-interpretative investigation was based on case study. The results of this study indicated that the importance of reading as a way to strengthen literacy processes has been neglected at the surveyed schools, due to the fact that reading has proved to be of secondary importance both in the pedagogical projects and in classroom practices. The practice of a teacher, observed and mentioned in this article, showed that difficulties in dealing with reading and literacy were explicit, especially when linguistic foundations, which are key to working with reading, were concerned. Therefore, this professional often takes action intuitively or uses pedagogical practices experienced during her own schooling time.

Keywords: Youth and Adult Education. Language and Education. Educational duties. 
Marinaide Lima de Queiroz Freitas

E-mail: naide12hotmail.com

\section{Valéria Campos Cavalcante}

E-mail:vccavalcante1@hotmail.com

Recebido em: 9/12/2013

Versão final recebida em: 10/2/2014

Aprovado em: 14/2/2014 